\title{
Challenges for government as facilitator and umpire of innovation in urban transport: the view from Australia
}

\author{
Dr John Stone, David Ashmore, Dr Crystal Legacy, Prof Carey Curtis
}

Dr John Stone, University of Melbourne

stoneja@unimelb.edu.au

David Ashmore, University of Melbourne

david.ashmore@unimelb.edu.au

Dr Crystal Legacy, University of Melbourne

crystal.legacy@unimelb.edu.au

Prof Carey Curtis, Curtin University

c.curtis@curtin.edu.au

Author Biographies:

John Stone is a Senior Lecturer in Transport Planning at the University of Melbourne. His research explores the political and institutional context for variation in international transport planning practice, with a focus on cities in Australia, Canada and German-speaking Europe. He has also worked in local government and as a community advocate for sustainable transport.

David Ashmore is a researcher at the University of Melbourne. He recently completed his doctorate which examines the symbolic aspects of transport choice across different cultures. David's professional background is in transport regulation and procurement; he has worked for consulting firms, universities, and the civil service.

Crystal Legacy is a Senior Lecturer in Urban Planning at the University of Melbourne. Crystal's research examines questions of urban conflict and citizen engagement with a current focus on the role of the citizen in contested transport processes in Australian and Canadian cities. Co-editor of Instruments of Planning: Tensions and Challenge for more Equitable and Sustainable Cities (Routledge, 2016).

Carey Curtis is Professor of City Planning and Transport at Curtin University, Director of Urbanet research network, and Guest Professor University of Gothenburg. Her research interests include city form and structure, transit-oriented development, personal travel behaviour, accessibility planning, institutional barriers to sustainable transport, governance and transport policy. 


\section{ABSTRACT:}

New economies based on emerging technologies for shared mobility and autonomous vehicles will shape future urban transport systems, but their potential impacts are uncertain. Internationally, government agencies face difficult challenges to effectively plan and regulate the deployment of these technologies for the common good, whilst simultaneously encouraging innovation. Being both a facilitator and an umpire is not an easy task.

This chapter draws on a series of interviews with public and private-sector actors in urban transport in Australia. Unsurprisingly, all private-sector respondents had significant concerns for the sustainability of their business in the emerging mobility markets, but it was generally acknowledged that without government support and partnership, a lack of structure and clarity could lead to natural monopolies with negative consequences for competition and the public good. Strong and clear government regulation is seen to be necessary to allow the sector to reach its maximum potential and have positive ramifications for both the public and the private good - outcome not always seen as compatible. Public-sector interviewees generally recognised that much of the necessary innovation was being shaped by the market, and that there had been a considerable loss of skills over decades from the state because of neo-liberal policies. So, some doubted the ability of the state to shape developments using currently available planning and public policy methods and feared that it would be difficult to regulate emergent markets to prevent monopolies emerging. On the other hand, some argued that many firms are looking to government for frameworks in which businesses can operate successfully by setting conditions in which risks could be managed.

This chapter discusses these issues, seeking to guide research agendas and to foster further debate. The evidence gained from these in-depth interviews helps focus attention on which forms of regulation might be required by industry. It also raises questions about the capacity of government agencies to effectively manage these complex transitions.

\section{KEYWORDS:}

1. Mobility transitions

2. Regulation

3. Monopolies

4. Privatisation

5. Competition

6. Co-production 
Challenges for government: the view from Australia

\section{Introduction}

Urban transport systems have many features that distinguish them from a classic 'market'. These include the natural monopolies of railway or toll-road networks, and the considerable public investments required for infrastructure and operations. This means that policy approaches derived from neo-liberal theory have limited value. Decisions about urban transport systems are politicised around issues such as environmental impact, equitable access to the benefits of city life, 'best value' for taxpayers, and the fair allocation of public space. These are matters that can be neatly summarised as the 'public good' although this is a slippery concept. Here, it is taken to be the objectively definable benefits that citizens might expect governments to deliver.

The entry of new private interests in communications and information technology, as well as the commercialisation of user-data, necessarily raises new questions about resisting monopolies, directing public investment and maintaining the public good in future urban transport systems. How will public ambitions to improve the social and environmental performance of our transport systems be met as these new and powerful interests deploy emerging technologies?

This chapter uses recent interviews with public and private-sector actors in Australia to explore both obstacles, and the opportunities for these two groups to come together to consider planning and regulatory responses to emerging technologies. In doing this, we want to go beyond simplistic binaries of the 'ossified public sector' and the 'nimble private sector'. We draw from existing literature on collaborative innovation and co-production which allows us to consider how productive engagement between the public and private sectors might help maintain or extend the public good during the current period of technological transition.

In the European context, where to some degree, the public sector remains a strategic leader, manager and regulator of existing urban services and infrastructure, co-production can take place through mechanisms of 'collaborative innovation' (Torfing, 2018; Agger \& Sørensen, 2018). An example can be seen in the emergence of MaaS in Helsinki (Hietanen, 2014; 2019). In Australia, however, where modes of urban governance are increasingly corporatised (Gleeson, 2018) and the state has been retreating from its historic role as a supplier of transport goods and services since the 1990s, the balance of power has become increasingly complex. Watson (2014) provides a useful guide to ensuring that imbalances of power are not ignored in attempts to find new approaches to communicative or collaborative planning; and the literature on co-production points to ways of imagining processes "through which inputs from individuals who are not 'in' the same organisation are transformed into goods and services" (Ostrom, 1996, p. 1073) while acknowledging inequalities in power. 
Challenges for government: the view from Australia

Our exploration of the options for state responses to manage new 'disruptive' technologies is mindful of unequal power relationships between governments, citizens and corporations and the potential for imbalances in sharing the benefits and risks of innovation.

To probe these issues and to draw out themes for future research, interviews were conducted in 2017 and 2018 with senior staff in public and private sector organisations with interests in the deployment of MaaS and AV technologies in Australian cities.

We had two overarching objectives:

1. To identify policy instruments that governments or industry might consider appropriate in managing the introduction of new transport technologies. Policy instruments are defined here as specific actions such as policies, contracts, or regulations that are designed to constrain or shape the way new technologies are deployed. Reardon (2020, ch. 8 in this volume) provides a useful framework to describe how policy instruments fit into the broader process of policy development and implementation.

2. To use the responses to the interviews to assist in exploring opportunities for the academic community to engage with government and industry practitioners in supporting processes, which lead to the creation of effective policy instruments.

Rather than approach these objectives directly, we organised our interviews around two practical questions that are of immediate concern to participants. First, we asked about the degree to which respondents considered that new technological developments might lead to undesirable monopolies over the platforms to be used to access and pay for new and existing transport services. Second, we asked respondents their opinion on the ways in which the emergence of new technologies might destabilise existing transit operations. This is of particular interest in cities like Melbourne where these operations are governed through complex contracts with international corporations (Department of Transport Victoria, 2019).

The answers to these questions, looked at in the light of our wider objectives, allow us to consider what lessons the Australian experience might have for other jurisdictions about the role of regulation and the nature of public and private sector cooperation. They also allow us to frame clear research questions for future case studies of practice in other cities around the world. Doherty's (2020, ch. in this volume) on multi-level governance provides some useful insights relevant to the complexities of managing technological transitions under Australia's federal system. 
Challenges for government: the view from Australia

We see our research as part of the international response to calls from Marsden \& Reardon (2017) and Dowling \& Kent (2015) to understand how governance arrangements can and should be shaped by new transport technologies and new modes of interaction between the public and private sectors.

\section{Research Approach}

The first series of six interviews was conducted in March and April 2017 with the public-sector. These respondents had responsibility for shared and AV mobility policy at managerial level within road, planning and regulatory agencies across the Australian public sector. The second series of interviews was conducted in late 2018 with private-sector staff. Participants were selected from companies with an existing stake in the urban transport sector or in the deployment of new technologies and so liable to some degree of risk from the emerging disruptions. These individuals also had some experience of interactions with state agencies on relevant issues.

Interview subjects were initially identified through the researchers' networks and subsequent 'snowballing'. Our combined sample size of eighteen is considered sufficient for thematic saturation (Guest et al., 2006). However, it was not easy to recruit participants. The political nature of these topics meant that many people we approached were not willing to go on the record: an obstacle that other researchers have also faced (Guerra (2016). To get agreement to participate, rigid participant anonymity was necessary. This included not only direct identifiers, but also identification by association or location.

Since the aim of this second phase of our research was to compare the opinions of actors from the private sector with those previously obtained from public-sector transport planners (Stone et al, 2018; Legacy et al, 2018), the results were analysed in relation to the key themes from the public-sector interviews rather than through an agnostic process of thematic coding. This places the work within the sphere of confirmatory thematic analysis (Braun and Clarke, 2006).

The two key themes were:

- the extent to which regulation is thought to be necessary;

- obstacles and opportunities for public-private cooperation to identify and maintain the public good.

\section{Findings}




\section{Public Sector perspectives}

Some public-sector respondents clearly understood the need for new technologies to be deployed in ways that strengthen transit systems as an alternative to the private car, and that this would require new responses from governments. Recognising, however, that much of the necessary innovation was being shaped by the market, and there had been a considerable loss of skills over decades from the state to the private sector as a consequence of neo-liberal policies, some doubted the ability of the state to shape developments by planning and public policy methods that have been in place for many decades.

All participants noted the need for state-driven regulations to ensure safety, but some preferred that other regulatory issues be managed through a 'light touch' from government in response to any emerging problems. They recognised that, within the public sector, the skills needed to critically appraise the benefits of the new technologies, and how to procure them as part of an integrated solution, were underdeveloped, because of both skills leakage and the nature of the technologies themselves. It would, in most cases, be unreasonable to expect that many civil servants would understand the technical nuances of the emerging disruptors:

The capacity of the public sector to understand the drivers that motivate private sector behaviour is going to be important ... A lot of the expertise is going to be held by the private sector, we need to build our capacity to be an informed consumer of services and advice (and) when the private sector holds expertise that the public sector doesn't, it can be very challenging to drive good ... outcomes. [Public Sector interviewee 1].

Interviewees argued that it would be difficult to regulate emergent markets to prevent monopolies emerging. Existing plans were becoming obsolete and new regulations are slow to move through the political process. Many felt that there was considerable risk of regulating "inappropriately" in an evolving market, where resources were finite:

Things are moving from (plans that were) written two years' ago - things have changed markedly. The planning cycle and the planning horizons have gone even more crystal ball than they ever were before. It's very hard to plan in such an environment. Regulation takes a long time to design and get in. If you try and foresee what's going to happen and try and regulate ahead of the curve, then you are probably going to get something wrong [Public Sector interviewee 5]. 
Challenges for government: the view from Australia

Although many respondents did feel that governments should leave the field free for private-sector innovation, some did hold a contrary position. One interviewee argued that many in the private sector were looking to government for frameworks in which businesses could operate by setting conditions in which risks could be managed:

I think that the (companies developing new technologies) are very aware that they need the active cooperation of governments, and (are) probably more (aware) than we as government... that they need this active cooperation. There are a number of examples -for example, with the trial that Volvo are doing in Gothenburg... the data, the infrastructure ownership, the rules under which people can use infrastructure... all of those things require very active and informed governments to be purchasers, regulators, policy makers and partners [Public Sector interviewee 2].

This pattern was also present during the development of MaaS in Helsinki, where the platform was first created by a state agency before being rolled out as an anti-monopolistic private body, sitting between the operators and the regulator (Hietanen, 2014).

This observation of the recognition of need for "active cooperation" between government and technology companies was confirmed in the private-sector interviews.

\section{Private sector perspectives}

As noted above, two key themes emerged from the public-sector interviews: reluctance to regulate digital and technological disruption; and consequent obstacles to forming partnerships with industry to manage the deployment of new technologies. Before looking in more detail at how the privatesector respondents viewed these questions, it is worth noting an interesting contrast between the two groups. On one hand, public-sector interviewees recognised the need to regulate for the common good (although recognising the need did not necessarily equate to knowing what should be done) but were largely focussed on limiting intervention in order to allow innovation to flourish. On the other hand, many (although not all) private-sector respondents were looking for a more ruleconstrained environment in which to build their businesses.

In this section, we summarise the responses on each of these themes.

\section{The necessity for regulation?}

The difficulties of regulating in an environment in which new developments are constantly occurring was acknowledged by all respondents. It was not clear how the emphasis, noted by Hensher (2017), 
on offering the lowest price for services in a typical competitive-tendering market could account for emerging risks to both purchaser and supplier. Introducing new regulations was seen to be especially difficult under long-term franchising arrangements, such as those in Melbourne, where significant parts of transit operations are currently outsourced under contracts which may not be competitively priced and where problems of a lack of transparency and the potential for internal cross-subsidies mean that pricing may not be competitive (Ashmore et al., 2018).

The views of respondents on the appropriate response to these difficulties fell along a spectrum. At the one end, some thought that governments should step back to allow innovation and flow.

... we've seen time and time again that businesses can thrive and develop more innovative solutions if there is flexibility ... and they have productive and cooperative working relationships with regulators... the private sector has the confidence to roll out innovative technological solutions in those markets (Private Sector interviewee 5).

Other participants felt that the public and private sector needed each other to work towards the common good drawing upon their relative spheres of influence. Contrary to what one might expect, not every private-sector interviewee put short-term profit maximisation ahead of a need to find sustainable solutions. The undesirable consequences of short-term profit maximisation were noted:

I tend to, perhaps, not have the greatest confidence in pure private-sector solutions. I think that's just my own experience. Dracula and the blood bank, yeah, I don't think that goes terribly well. So, I guess I'd lean more towards the state-regulated solution. What precisely that should be obviously is being worked out, it's a complex question. (Private Sector interviewee 4).

An ancillary theme was the view that the state was unable to predict every eventuality and should or could only step in when things failed and the public good was compromised. This was seen as the historical pattern for advances in transport technologies:

...the railways were innovative in their day. The private automobile was innovative in its day. So, innovation and disruption are very transitory periods for new technologies and, eventually, the regulatory regime catches up. To some extent, the government doesn't know where it needs to intervene because the normal operating patterns haven't been established (Private Sector interviewee 8).

As also seen in the public-sector interview, respondents called for "pragmatism" in response to innovation but could not say what form responses should take, nor who would dictate at what point regulation might be necessary. The notion of the transfer of both commercial and political risk was 
discussed, with governments seen to 'wear' political risk in event of system failure, regardless of the content of a contract:

While some public servants might see themselves as policy entrepreneurs and see themselves shaping government policy, that's probably the minority .... The dilemma for government ... is the impact of unintended consequences. Private sector can wear that. If they're successful, they become wealthy. If they're not successful, they fail. Nobody is concerned with a private-sector company failing. It's seen as part of the process. The government, on the other hand, doesn't have that luxury. A failed government program is generally regarded as a bad thing with political consequences, so they become highly riskaverse.... It then puts them in a position of always 'catching up'. (Private Sector interviewee 8).

Interviewees saw several interconnected reasons for governments to step back from imposing regulations. These included the complexity of the issues and the desire of politicians to be seen to be leading the introduction of new technologies ahead of competing jurisdictions. Other commentators have argued that such pressures are compounded by short electoral cycles (three years for Australia's national government, up to four years for state administrations which hold the key responsibilities for urban transport systems) which necessitate quick wins and often discourage longterm strategic planning practice. (O'Flynn et al., 2011).

While the role of regulation was a dominant theme in the interviews, the need for state planning and guidance through the planning process was also raised. In line with themes flagged in the development-industry press (for example Howell, 2018), one participant argued that governments had a role to play in helping guide developers on the transport infrastructure they would need to provide as transport technologies evolved:

The planning system must have a role in what it allows to happen, and what developers are required to build and provide. At the same time, the planning system is there, to an extent, to protect the surrounding community as well, and to ensure that (things like) car parking are provided appropriately, and managed appropriately ... how do we facilitate a shared-mobility outcome now? What is facilitating that shared-mobility outcome in 15 years' time? The trickiest question is, how do we transition between the two? (Private Sector interviewee 6). Maintaining the public good in an atmosphere of partnership - co-production Interviewees, both public and private, understood that partnership between government and industry was inevitable given private sector control of technological innovations. Some interviewees saw such 
partnerships operating at the level of data-sharing as a spin-off from the capabilities of new vehicle technologies:

There has to be some partnering there between government and the holders of data. I know that (cars are now) very sophisticated, they read the road surface, so they know where the potholes are, they know the state of the roads. That is extremely useful to government in terms of maintenance, and if (cars are) collecting that data anyway why would the taxpayer want to pay governments to go around and check the safety of the roads. We can save that cost by pulling in data from the private sector. We can only do that if there's a good relationship between the private sector and the regulator. (Private Sector interviewee 12).

The next level of partnerships discussed by the private sector concerned standardisation of systems. This is challenging in the public policy context. When the data for the common good and sound planning lies outside the government, how does the government ensure access? Might this be used as leverage in regulatory discussion: could the state become actively involved in data ownership as a condition of market access? A degree of 'give and take' was seen to be necessary. As in the oftencited 'Betamax/VHS' battle for the hardware market via data standardisation, it was felt that this would be won by might rather than right: the winner would be the one who saturated the market thereby gaining critical mass long before the state could implement a 'plug and play' standard. This might not be in the wider public or commercial interest:

If you went back a couple of decades there were those stand-alone operating systems, and gradually there's been (some) standardisation ... the issue is: did anyone build up a monopoly unfairly? Well the argument might be no, but now having a monopoly... are you now dominating the market and stopping any competition arising or crushing what's left, and the answer to that might be yes [Private Sector interviewee 2].

So, there was recognition of potential problems, but no clear direction towards a solution.

Beyond these instrumental partnerships, there is a perception that states are not always able to engage in deeper partnerships to shape the deployment of new technologies to meet wider objectives due to lack of government capacity, orientation, or skills. It was suggested that the let the market decide' approach might be a smokescreen for inaction:

There is a certain sense to (letting the market decide), but I also think that it is a big cop out. I think governments should be saying: we don't know what's going to happen, but we know what we'd like to happen. Instead, it is just too hard ... We'll talk about ... the fact that 
Challenges for government: the view from Australia

technology is too hard to predict and we don't want to get in the way, (but) ...that is just code for doing nothing. (Private Sector interviewee 2).

The "nimble government" desired by most interviewees was seen as unlikely to emerge given current bureaucratic and democratic processes. It was noted that the public service contained deeply competent and knowledgeable people, fully conversant with the issues at play, but their hands were to some degree tied, because if they alerted politicians to the difficulties involved and the contradictions at play, it could ruin their careers:

I would not give them an A, B or C if I was doing high school scoring with their planning. I feel sorry for some of the people in the state legislature that get it but are surrounded with a system that doesn't want that sort of alternative thinking. It's too hard to deal with... the realities that may be coming in a decade or so - often it's scary and not necessarily a good news story. ...if people in government did question the status quo I am pretty sure it would be career limiting. Their political masters would likely go and find someone less insightful for their role. (Private Sector interviewee 7).

This political and operational weakness of Australian transport agencies, described in many interviews, was seen by some as an obstacle to effective regulation.

I think governments are still floundering ... I don't think that the ride-hailing situation has really taught them anything. I know some State governments thought that they did a good job because they just got out of the way and let it happen and regulated around it, but I think that there are some people in the industry who would take a different view (Private Sector interviewee 10).

Given this weakness, it will be important to look outside Australia to cities with relatively more powerful city governments and transport agencies for models for engagement with the private sector and the development of appropriate policy instruments.

Useful examples can be found in the responses to the arrival of competing ride-hailing platforms in London (Colley, 2019), Oslo (OECD, 2018) and Los Angeles (Chen, 2019). Each of these cities has tried a different approach to protecting aspects of the public good such as passenger safety and reduced use of public and active transport modes in the face of increasing public acceptance and demand.

Another example is the set of 'ground rules for autonomous driving' being developed by planners at the City of Vienna. These set out the city's traffic management objectives, and state that AVs should be adapted to public spaces rather than the other way around, and that there should be no 
expectation of public funding for complex infrastructure to accelerate transitions autonomous driving (Stadt Wien, 2019).

As with all policy transfer, however, the recipient nation's capability to successfully adopt the policy is highly dependent upon a variety of localised factors (Stead, de Jong, \& Reinholde, 2010; Stone, Stead, Zeibots, Baumann, \& Bell, 2014).

\section{Where to now?}

The aim of this paper was to examine the need, purpose and form of policy instruments that governments or industry might consider appropriate in managing the introduction of new transport technologies.

The interview findings suggest that there is a need for government to regulate emergent technologies in the urban transport sector, and that many in the public and private sectors share similar fears about negative outcomes from emergent monopolies. This is an interesting finding as it has the potential to shift the discussion about regulation away from a binary 'regulate or not' towards a more nuanced, complex and context-dependent discussion about regulation as something that might be co-produced by a range of actors. It also opens the way, in the Australian context of outsourced service and infrastructure provision, to find ways to build flexibility into contracts without additional cost.

Answers to questions of 'what should be regulated' also began to emerge from the interviews.

The rise in platform technologies, and changes to the way people expect to travel, is changing the transport sector in new, exciting, and at times, alarming ways. This research has demonstrated that there are similar concerns surrounding the regulation of this transition. The interviews showed that many participants felt that monopolies are not only undesirable from the perspective of the public good, they are also undesirable for private firms unless they are the monopoliser. There was a sense that both sides were seeking to understand the potential impacts of disruption, even if the values and priorities of different parties were not yet clearly articulated, and often logically contradicted each other.

While it may have been anticipated at the outset that some private sector interviewees may be strongly anti-regulation, many of the interviewees stressed that managing risk in their business entailed maintaining open and competitive markets, and this needed the certainties offered by regulation. 'Disruptive' business would disrupt existing and stable business models, as well as public policy. This is an interesting perspective, as there may in some case be a temptation to see the private sector as monolithic - this preliminary research suggests that this is not the case. Interviewees noted 
the need for the state to oversee but not necessarily do. As an example, in some of the transit franchises operating in Australia, the state retains ownership of all the assets. So, it is possible to replace operators and change contract conditions at regular points of tendering (typically every 7 or 15 years). Franchise change has had various causes, some political, and some the result of inappropriate allocation of risk at the bidding stage (Ashmore, Stone \& Kirk, 2018; Stone, 2010). This has happened on several occasions, but at no point were the franchisee's revenue or patronage streams dramatically disrupted over the life of their contract, as could be the case under emerging technology transitions, if, for example, there was rapid growth in use competing ride-sharing services.

Perhaps unsurprisingly, questions were raised about the definition of the public good: is it social or economic? This mirrors the political discussions that take place in many societies. Some privatesector actors sought to narrow the definition of the 'public good' to the commercial good. This is clearly a concern when the profit imperative is the rationale for decisions about coverage and service levels for ride-sharing in suburban locations. Without regulation or formal contracts in place, the most vulnerable may often remain in conditions of transport disadvantage. This is likely to be the case on the urban fringe, where emergent technologies are unlikely to be able to cater to this need without some form of public subsidy. Models for allocating and monitoring such subsidies are likely to differ substantially from those used for route-buses. This is an important topic for further international and local research and debate. How can ride-hailing firms be contracted to supply definitive off-peak services when they are demand responsive, and in many cases do not claim to employ people? Attempts to establish public-sector alternatives to commercial ride-hailing in suburban markets in Berlin and Vienna have struggled to be competitive.

The basic mechanism of 'market forces' and its strengths and weaknesses were common themes among both public and private sector. Some respondents relied on the assumption that all aspects of the market mechanism would manifest themselves in the price: as is the case in the classic 'externalities' argument relating to congestion charging (see Powell, 2001). There was discussion of market forces regulating the pricing mechanism, but the evidence form experience is that this has not always proven effective: it is unlikely that competition in the market produces sound public outcomes if there are loopholes at play (Ashmore and Mellor, 2010). When some companies can afford to offer 'loss leaders' (products sold at a loss to attract customers), competition can be supressed for a short period until monopolies emerge, and then prices can be raised. Furthermore, in maintaining a competitive market different firms have different lines of capital to draw upon, each with their own distinctive short and long-term imperatives. This can further distort the competitive landscape. In statements about the effectiveness of market forces, a significant proportion of respondents saw 
monopolies as a potential problem: monopolies are only not a concern for the entity likely to form the monopoly.

Again, this was a problem that was stated without a clear direction to a solution. Clearly issues of market power are fundamental to the co-production of workable means of avoiding monopolies.

The similarities in the positions of our interviewees in the public and private sector adds an important dimension to critiques of the Australian state as an increasingly corporatised entity. Stereotypes of a rigid inefficient state and a private sector seeking to escape its restrictive clutches, were, in our context, not borne out. This suggests that the planning of future transport provides an opportunity for co-production or co-design of regulation, strategic planning and future policies. Transparent debate will be important to ensure that such co-production is aligned with the values of a public-oriented planning systems to produce an integrated system of mobility and access into the future.

This debate needs to start from the reality identified through our interviews. Public and private actors share some understandings of the issues at stake, but because of institutional constraints, the difficulty to track the rapidly changing trajectories of commercial development of new technologies, and limited conceptions of potentially useful policy instruments, neither group appears able to do more than articulate the problems.

International academic collaborations can play a vital role in describing the range of policy instruments being proposed and enacted in different jurisdictions and contextualising their relevance for other cities. Engaged academic research can also help to create processes and structures to bring the public and private sector together as agents facing similar dilemmas and to create the conditions for effective co-production of workable solutions. This is a complex undertaking, with the state expected to be an enabler and an umpire, and the private sector likely to be in favour of competition until they are the ones controlling the market.

\section{Acknowledgements}

The authors would like to thank all the anonymous interviewees for the time and thought that they contributed to our conversations. The research was supported by funding from the Melbourne Sustainable Society Institute (MSSI) at the University of Melbourne, and from K2, the Swedish Knowledge Centre for Public Transport. 


\section{References}

Agger, A., \& Sørensen, E. (2018). Managing collaborative innovation in public bureaucracies. Planning Theory, 17(1), 53-73.

Ashmore, D., Stone, J., Kirk, Y., (2018). The Need for Greater Transparency When Assessing the Performance and Prospects of Melbourne's Rail Franchise Contracts. Urban Policy and Research, 115. https://doi.org/10.1080/08111146.2018.1486296

Ashmore, D.., Mellor, A., (2010). The 2008 New Zealand public transport management act: Rationale, key provisions, and parallels with the United Kingdom. Research in Transportation Economics, Reforming Public Transport throughout the World, 29, 164-182.

Braun, V., Clarke, V., (2006). Using thematic analysis in psychology. Qualitative Research in Psychology 3, 77-101. https://doi.org/10.1191/1478088706qp063oa

Chen, M., (2019). 'Uber and Lyft Hate This Bill'. https://www.thenation.com/article/uber-lyftcalifornia-ab5/. Accessed 24 January 2020

Colley, J. (2019). 'Uber's troubles in London are nothing compared to the bigger picture'. https://theconversation.com/ubers-troubles-in-london-are-nothing-compared-to-thebigger-picture-127746, Accessed 24 January 2020

Department of Transport Victoria. (2019). Melbourne's train and tram contracts. Retrieved from https://transport.vic.gov.au/getting-around/public-transport/train-and-tram-contracts, 9 December 2019

Doherty, I (2020). Crafting effective policy instruments for 'Smart Mobility': can Multi-level Governance deliver? in A. Paulsson \& C.H. Sørensen (eds.) Shaping smart mobility futures. Governance and policy instruments in times of sustainability transitions. Brinkley, UK: Emerald

Dowling, R., \& Kent, J. (2015). Practice and public-private partnerships in sustainable transport governance: The case of car sharing in Sydney, Australia. Transport Policy, 40, 58-64.

Gleeson, B. (2018). The Metropolitan Condition. In S. Hamnett \& R. Freestone (Eds.), Planning Metropolitan Australia. Abingdon: Routledge.

Guest, G., Bunce, A., Johnson, L., (2006). How many interviews are enough? An experiment with data saturation and variability. Field Methods 18, 59-82.

Guiver, J.W., (2007). Modal talk: Discourse analysis of how people talk about bus and car travel. Transportation Research Part A, 41, 233-248. https://doi.org/10.1016/j.tra.2006.05.004

Hietanen, S. (2014). Mobility as a Service-The new transport model? Eurotransport, 12, 26-28.

Hietanen, S. (2019). A Brief History of Maas Global, the company behind the Whim app, https://whimapp.com/history-of-maas-global/, Accessed 2 December 2019

Howell, M. (2018). What property developers need to know about the future of car parking. Retrieved from https://theurbandeveloper.com/articles/what-property-developers-need-toknow-about-the-future-of-car-parking, 21 September 2019.

Lapadat, J., (2010). Thematic analysis, in: Encyclopaedia of Case Study Research. SAGE Publications, Thousand Oaks, CA, US.

Legacy, C., Ashmore, D., Scheurer, J., Stone, J., Curtis, C., (2018). Planning the driverless city. Transport Reviews, 1-19. https://doi.org/10.1080/01441647.2018.1466835

Marsden, G., \& Reardon, L. (2017). Questions of governance: Rethinking the study of transportation policy. Transportation Research Part A: Policy and Practice, 101, 238-251. 
Newton-Smith, W., (1981). The rationality of science, in W.H. Newton-Smith (Ed.), International Library of Philosophy, Routledge \& Kegan Paul, London.

OECD, (2018). Taxi, ride-sourcing and ride-sharing services - Note by Norway, Working Party No. 2 on Competition and Regulation, Directorate for Financial and Enterprise Affairs Competition Committee, OECD.

O'Flynn, J., Vardon, S., Yeatman, A., Carson, L., (2011). Perspectives on the Capacity of the Australian Public Service and Effective Policy Development and Implementation. Australian Journal of Public Administration 70, 309-317.

Powell, T., (2001). The principles of transport economics. PTRC, London.

Reardon, L (2020) Smart mobility as a catalyst for policy change towards low carbon mobility? in A. Paulsson \& C.H. Sørensen (eds.) Shaping smart mobility futures. Governance and policy instruments in times of sustainability transitions. Brinkley, UK: Emerald

Stadt Wien, (2019), 'Basic positions for autonomous driving', https://www.wien.gv.at/stadtentwicklung/strategien/autonomes-fahren.html (in German), Accessed 17 September 2019.

Stead, D., de Jong, M., \& Reinholde, I. (2010). West-east policy transfer: the case of urban transport policy, in P. Healey \& R. Upton (Eds.), Crossing Borders: international exchange and planning practices. London: Routledge.

Stone, J., (2010). Turning over a new franchise: Assessing the health of public transport management in Melbourne. Paper presented at the 33rd Australasian Transport Research Forum, Canberra.

Stone, J et al., (2018). 'Planning for disruptive transport technologies: how prepared are Australian transport agencies?', in Marsden, G \& Reardon, L (eds), Governance of Smart Mobilities, London: Emerald Publishing.

Torfing, J., (2018). Collaborative innovation in the public sector: the argument, Public Management Review, DOI: 10.1080/14719037.2018.1430248.

Watson, V. (2014) Co-production and collaboration in planning, Planning Theory \& Practice, 15, $1,62-76$. 
Challenges for government: the view from Australia 


\section{University Library}

\section{- M M N E R VA A gateway to Melbourne's research publications}

Minerva Access is the Institutional Repository of The University of Melbourne

Author/s:

Stone, J;Ashmore, D;Legacy, C;Curtis, C

Title:

Challenges for Government as Facilitator and Umpire of Innovation in Urban Transport: The View from Australia

Date:

2020-01-01

Citation:

Stone, J., Ashmore, D., Legacy, C. \& Curtis, C. (2020). Challenges for Government as Facilitator and Umpire of Innovation in Urban Transport: The View from Australia. Paulsson, A (Ed.). Sorensen, C (Ed.). Shaping Smart Mobility Futures: Governance and Policy Instruments in times of Sustainability Transitions, (1), pp.105-118. Emerald Publishing Limited.

Persistent Link:

http://hdl.handle.net/11343/252708 